\title{
The Journal of Morphological Sciences and the COVID-19 Pandemic
}

\author{
Valéria Paula Sassoli Fazan' \\ ${ }^{1}$ Department of Surgery and Anatomy, School of Medicine of Ribeirão Preto, University of São Paulo, Ribeirão Preto, SP, Brazil.
}

\section{Dear Authors,}

2020 was a very atypical year for all of us. By this time, last year, none of us has had an idea of what was about to happen. All of a sudden, we had to quickly incorporate new words into our daily language and recognize their impact on our regular and "normal" life: coronavirus, $70 \%$ gel alcohol, mask mandates, social distancing, viral load, google meet, virtual meetings, lockdown, home office...

Most of us, beyond being scientists, are also university professors. We had to suddenly change our ways of teaching, forced into the virtual world without previous training, doing an enormous amount of extra work, most of the times increasing the workload by 2-3 times, so we could keep our students on track, despite the great fear, anxiety, and confusion.

Our research laboratories had to close their doors, greatly impacting negatively on our productivity. "Home office" research was impossible. The world's economical impairment brought a very hard time obtaining financial research support. Thus, despite the continuous teaching activity, research was brought to a complete halt.

The Journal of Morphological Sciences suffered a direct impact from the COVID-19 Pandemic. Financial support was incredibly reduced since the Brazilian Society of Anatomy, the journal provider, suffered an enormous economic hardship with the COVID-19 pandemic. Also, our authors had their laboratories reducing activity during this odd year of 2020, decreasing submissions.

Nevertheless, with the herculean work of the Brazilian Society of Anatomy directors, all our authors, our editorial board members, our associate editors and, the editor myself, we are resuming the Journal of Morphological Sciences publication, now published independently, through the Brazilian Society of Anatomy publisher. We ensure that we will continue to work very hard to keep the high quality of our journal.

For now, all we can say is thank you. Thank you for your continuous support. Thank you for your resiliency and understanding. Thank you for your dedication to science, and innovation in teaching. We know that this strange situation will end. We all want to go back to our normal lives. We made history and the Journal of Morphological Sciences admires your persistence, strength, and character to keep our journal stronger!

Thank you!

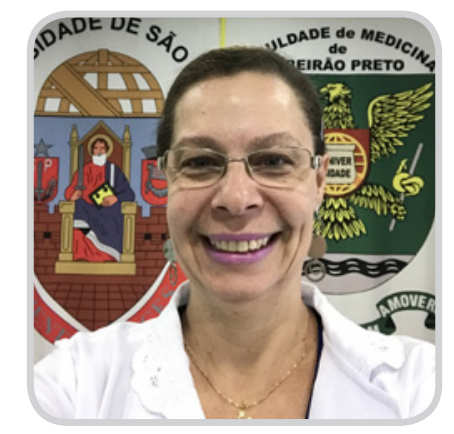

Valéria Paula Sassoli Fazan, M.D.; Ph.D.

Associte Professor Department of

Surgery and Anatomy School of Medicine

of Ribeirão Preto University of São Paulo

Journal of Morphological Sciences Editor-in-Chief

\section{Address for correspondence}

Valéria Paula Sassoli Fazan, MD, PhD, Departamento de Cirurgia e Anatomia, Escola de Medicina de Ribeirão Preto, Universidade de São Paulo, Av. dos Bandeirantes, 3900, Monte Alegre, Ribeirão Preto, SP, 14049-900, Brazil

Email:vpsfazan@yahoo.com.br 